Borneo Journal of Sciences \& Technology, Volume (3), Issue (1), Pages: 43-50

DOI: http://doi.org/10.3570/bjost.2021.3.1-07

e-ISSN: 2672-7439

(C) 2018, UCTS Publisher.

Submitted: $20^{\text {th }}$ September 2020 $\quad$ Accepted: $25^{\text {th }}$ October 2020 $\quad$ Published: $31^{\text {st }}$ January 2021

\title{
Characteristics of Diurnal and Nocturnal Lightning Activities in Sarawak, Malaysia
}

\author{
${ }^{1}$ N. A Ramlee, ${ }^{2}$ N. A Ahmad, and ${ }^{3}$ Z. A. Baharudin \\ ${ }^{1}$ School of Engineering and Technology, University College of Technology, Sarawak, Malaysia \\ ${ }^{2}$ Institute of High Voltage \& High Current, Universiti Teknologi Malaysia, Johor, Malaysia \\ ${ }^{3}$ Fakulti Teknologi Kejuruteraan Elektrik \& Elektronik, Universiti Teknikal Malaysia, Melaka, Malaysia
}

\begin{abstract}
Malaysia has a very high lightning activities rate that had been recorded every year. Yet, there are still too many lightning features that have not been explored in Malaysia especially in the eastern part of the country. This study presented diurnal and nocturnal lightning characteristics recorded in Sibu, Sarawak. The lightning electric field signal was detected using parallel plate antenna. The waveform was analyzed using PicoScope Software. Four important parameters of negative first and subsequent return stroke were measured namely normal electric field peak voltage, zero crossing time, zero to peak rise time and 10 to $90 \%$ rise time. Ten samples of diurnal first return stroke and 10 subsequent return strokes were presented in this study. Same amount of samples were measured for nocturnal lightning. Averagely, normal electric field peak voltage and zero crossing time for diurnal lightning were higher for both first and subsequent return strokes compared to nocturnal lightning. Contrarily, zero to peak rise time and 10 to $90 \%$ rise time of diurnal lightning were shorter for both first and subsequent return strokes compared to nocturnal type of lightning. The findings in this research conspicuously enhanced the knowledge about the variations of lightning characteristics in Malaysia.
\end{abstract}

Keywords: Negative lightning, Return stroke, Parallel plate antenna, Lightning characteristics.

\section{INTRODUCTION}

Lightning is one of the Mother Nature on earth. Each bolt of the lightning contains up to 1 billion volts of electricity [1]. Lightning normally associated with thundercloud which brings destruction to the earth [2, 3]. It occurs when air fluctuates in the cloud resulting in the separation of positive and negative charges. Lightning has a bright light that is formed during the release of electricity into the atmosphere. It can occur during electric stretching at two separate points in one cloud, between the two clouds, between cloud and air, and also between the cloud and the ground. Cloud to ground (CG) lightning is the most hazardous to living things on earth. The electrical discharge or lightning is produced when electrical charges on the ground and the atmosphere are large enough to overcome the effect of air insulation. CG lightning can be categorized into positive and negative type based on their initiating charges [4]. The negative CG is a typical compared to positive CG [5]. Most of the lightning investigation conducted around the world observed only less than $10 \%$ of the positive lightning events [6-8] that make them very scarce. There are several lightning parameters that are vital in estimating a lightning protection system sensitivity or accuracy such as the operating threshold voltage or current. This includes normal electric field peak voltage $\left(E_{n}\right)$, zero crossing time $\left(T_{z c}\right)$, zero to peak rise time $\left(T_{Z P}\right)$ and $10 \%$ to $90 \%$ rise time $\left(T_{10-90}\right)$ which measured in this study. These parameters reflect to the maximum possible peak and energy produced in a lightning events [9]. Thus, lightning studies are considered important to produce a better design of lightning protection system that can be applied in Malaysia.

In Malaysia, various studies had been conducted to investigate effect of locations to the characteristics of lightning. Wooi et al. [10] analyzed lightning parameters in Johor and Malacca located in the peninsular Malaysia. They measured lower value of the lightning parameters compared to those generated in the temperate regions. Even lightning characteristics in the tropical region itself varies according to the geographical location of the lightning events and type of thunderstorm [11, 12]. Apart from that, there are also studies that have been conducted to analyze lightning characteristics based on different lightning types such as negative and positive narrow bipolar pulses [13], negative lightning flashes [14, 15], and positive lightning flashes [16]. Besides, lightning data obtained from Malaysia was compared to other regions with

Corresponding Author: Nor Asrina Binti Ramlee, University College of Technology, Sarawak, Malaysia,

Email: asrina@ucts.edu.my 
different meteorology as reported in $[10,17,18]$. All of the studies conducted in Malaysia were set up in West Malaysia. Due to that reason, this study intends to analyze the lightning characteristics in different geographical region that is in Sibu, Sarawak, located in the eastern part of Malaysia. It focuses to investigate the diurnal and nocturnal lightning characteristics variation. Diurnal is related to activity occurs during day time only and on the contrary, nocturnal related to activity which only occurs during night time [19]. It was hoped that the data analyzed in this research will be able to enhance the understanding on the lightning characteristics occurred throughout Malaysia. The diversity of lightning studies in Malaysia will definitely reduce the literature gap between Malaysia and other advanced countries in the world.

\section{INSTRUMENTATION}

A measurement field campaign was set up in the vicinity of University College Technology Sarawak (UCTS) $\left(2^{\circ} 20^{\prime} 29.0^{\prime \prime} \mathrm{N} 111^{\circ} 50^{\prime} 38.8^{\prime \prime} \mathrm{E}\right)$. The vertical electric field from lightning flashes were captured by using one parallel plate antenna, similar to the one developed by Garvan and Fernando [20]. The block diagram of the measurement set up is illustrated in Figure 1.

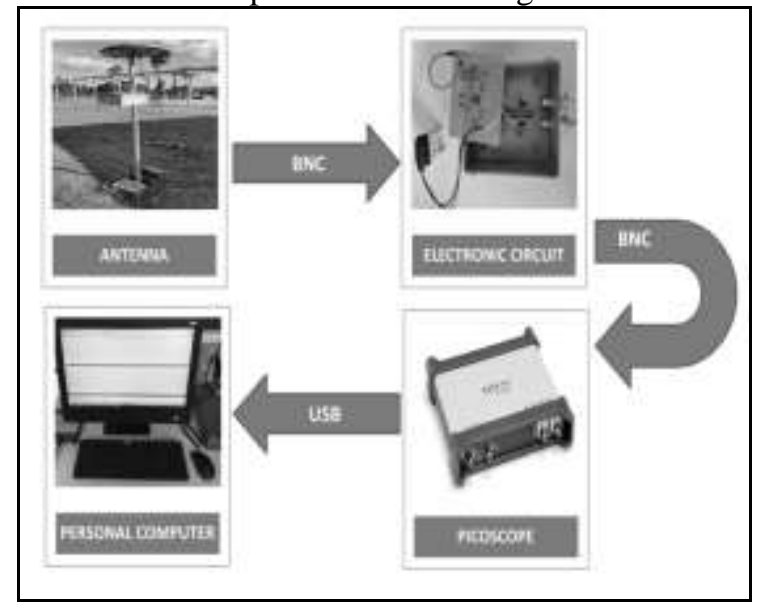

Figure 1: Block diagram for the measurement set up connection.

The electric field data was recorded using PicoScope which is an advanced oscilloscope and displayed using its pre-installed software in a personal computer via universal serial bus (USB) cable. A RG58 coaxial Bayonett Neill-Concelman (BNC) cable was used to connect the antenna and buffer circuit and also to connect the output of the buffer circuit to the oscilloscope. The parallel-plates antenna is composed of two parallel metallic plates, separated by a $3 \mathrm{~cm}$ thickness of insulator and was perpendicularly oriented to the direction of vertical electric field. The bottom plate was connected to the ground by insulated pure copper grounding cable. The antenna was placed at approximately 30 meters away from the control room. Due to the mismatch of the output impedance of the antenna and the input impedance of the oscilloscope, there is a need to insert a buffer circuit in between the antenna and oscilloscope. This is because buffer circuit is a device which has very large input impedance and small output impedance. The antenna has larger output impedance compared to the input of the impedance of the oscilloscope. The oscilloscope might be damaged if the induced voltage on the antenna is too high. Plus, the antenna has frequency-dependent output impedance that is an extremely large frequency will further increase the output impedance of the antenna. The voltage drops at the oscilloscope will vary with the frequency of the detected electric field, so the buffer circuit will also protect the oscilloscope against extreme voltages as well. Output of the buffer amplifier were digitized at rates of $20 \mathrm{MS} / \mathrm{s}$ with a vertical resolution of 12-bit, 200 $\mathrm{MHz}$ PicoScope. In this study, a negative return stroke was identified as a positive field change as applied in atmospheric sign convention concept. Diurnal lightning activity was observed starts from sunrise time until sunset time, whereas it was vice versa for the nocturnal activity. According to [21], average sunrise time in Malaysia is at $6 \mathrm{am}$ and sunset is at $7 \mathrm{pm}$. Thus, this study was conducted based on the timeline.

\section{DATA ANALYSIS}

Figure 2 displays the first sample of electric field waveform of FRS (first negative return strokes) from diurnal lightning which was retrieved from Picoscope Software. The measured peak voltage $\left(V_{m}\right), T_{z C}, T_{p}$ and $T_{10-90}$ were carefully analysed from the waveform. The normal electrical field, $E_{n}$ and the voltage measured, $V_{m}$ is related to measuring system factor, $F_{\text {meas }}$ as shown in Equation (1). Based on the calibration procedures done by Galvan and Fernando, different effective antenna height, $d_{\text {eff }}$ generates various measuring system factor, $F_{\text {meas }}$ as shown in Equation (2). All the equations derivation were comprehensively discussed in [20]. From the reference, $F_{\text {meas }}$ produced by $1.5 \mathrm{~m}$ of antenna height is 20.6037 and this value was employed in this current experimental set up. Thus, the equation for the normal electric field, $E_{n}$ in this study is stated in Equation (3). This study analyzed 10 samples of FRS diurnal, 10 samples of subsequent return stroke (SRS) diurnal, 10 samples of FRS nocturnal and 10 samples of SRS nocturnal obtained in March and July 2020, respectively. 


$$
\begin{aligned}
& F_{\text {meas }}=\frac{E_{n}}{V_{m}} \\
& F_{\text {meas }} \propto \frac{1}{d_{\text {eff }}} \\
& E_{n}=20.6037\left(V_{m}\right)
\end{aligned}
$$

Equation (3)

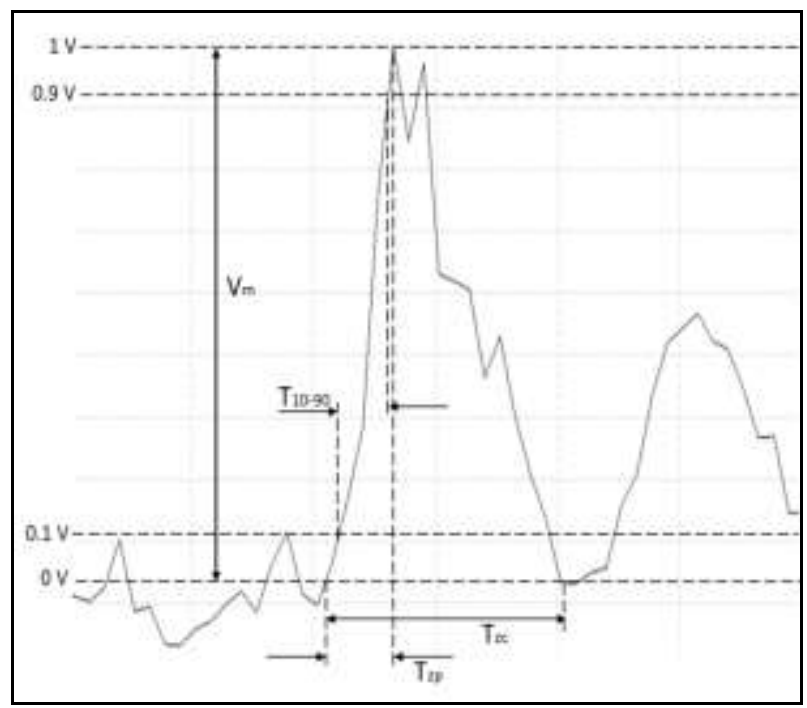

Figure 2: Negative lightning electric field for Sample 1

\section{a) Comparison Between Diurnal And Nocturnal For FRS AND SRS}

Day and night are meteorology phenomenon with variation of temperature and humidity and that probably influence lightning activities and characteristics. Generally, temperature is higher during diurnal activity in daytime compared to nocturnal in nighttime. As in Sibu, daytime temperature is averagely $30^{\circ} \mathrm{C}$ and can be up to $40{ }^{\circ} \mathrm{C}$, whereas night temperature is $23^{\circ} \mathrm{C}$ [22]. Thus it can be considered reasonable if diurnal lightning consists of higher FRS peak amplitude because of higher temperature compared to nocturnal. As presented in Figure 3, the $E_{n}$ value of FRS for diurnal lightning is $15 \%$ higher related to FRS of nocturnal lightning. Besides, warmer season produced higher lightning electric field amplitude as reported in [23, 24]. However, these findings are not in agreement with data measured in Guangdong Province in southern China analyzed by Zheng et al. [25] . Most of the high peak amplitude lightning events were observed during cold season compared to summer monsoon. This discrepancy is most likely due to climate difference. Guangdong is located at subtropical monsoon climate with rainy summer and dry winter. Besides, United State of America (USA) has various climate zones. By using data collected across the entire continent, Chronis et al. [26] found that nocturnal lightning produced higher peak amplitude compared to diurnal events which is also dissent from the results in this study. The highest difference parameter between FRS for diurnal and nocturnal is their mean value of $T_{z c}$. Figure 3 shows that FRS for diurnal produced $72 \%$ higher value than FRS for nocturnal lightning. This was most probably due to the higher cloud base height during the day. According to [27], the cloud base height is directly proportional to the gap between surface temperature and the dew point. Based on data presented in [21], diurnal lightning for this study was acquired when the surface temperature and the dew point was averagely $3.2^{\circ} \mathrm{C}$ in difference. Meanwhile, it was averagely $1.2^{\circ} \mathrm{C}$ gap between the surface temperature and the dew point during nocturnal lightning observation. As inferred by Cooray, the vertical length of the lightning channel that initiates the discharge can affect the $T_{z c}$ [28]. The vertical channel for lightning is approximately equal to the height of the initial charge layer in the thundercloud. Thus, longer vertical lightning channel produces longer $T_{z C}$. Generally, daytime is warmer than at night. Thus, it's not surprising when Ishii and Hojo also found $T_{z c}$ was 97.5\% longer during summer compared in winter [29]. As observed in Nag and Rakov [30], $T_{z p}$ and $T_{10-90}$ were tend to be shorter in a warmer climate which having higher temperature and vice versa. As in [31], lightning data from Brazil as a warmer country was compared to Japan. It was observed that $T_{Z P}$ and $T_{10-90}$ in Brazil were $57 \%$ and $15 \%$ respectively shorter compared to Japan lightning data. It can be seen that result of present study is in agreement with their findings as can be observed in Figure 3. $T_{z p}$ for FRS obtained in day time with higher temperature is $27 \%$ shorter than FRS in night time. Meanwhile the $T_{10-90}$ for diurnal FRS is 9\% shorter compared to nocturnal FRS. Figure 4 shows the comparison of SRS data for diurnal and nocturnal lightning. It can be observed that SRS data produced similar pattern with FRS lightning for diurnal and nocturnal as discussed previously. SRS for diurnal samples are having only slightly higher $E_{n 1}$ value which is $5 \%$ than nocturnal. The SRS $T_{z C}$ mean value for diurnal is $89 \%$ higher than nocturnal. The difference is huge compared to FRS samples. The mean value for diurnal SRS $T_{Z P}$ and $T_{10-90}$ are $32 \%$ and $9 \%$, respectively, shorter compared to SRS for nocturnal lightning. 


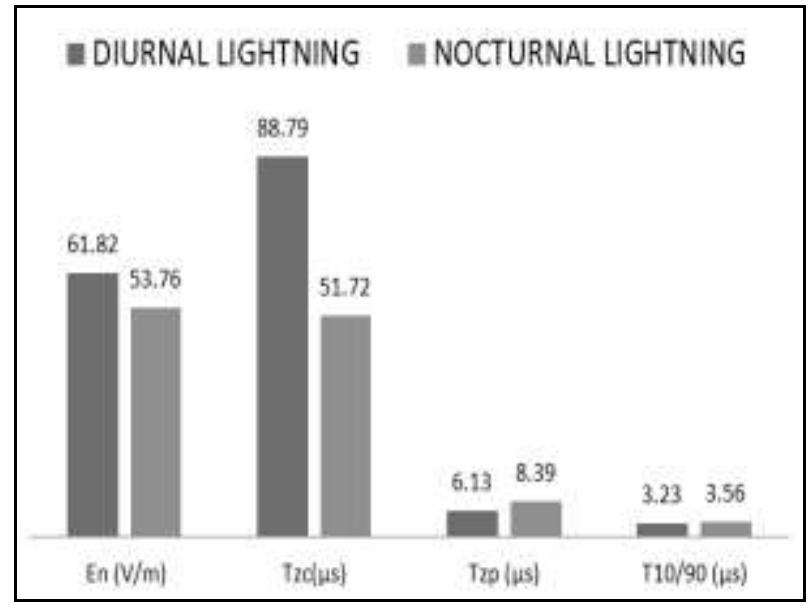

Figure 3: Comparison for FRS Parameters

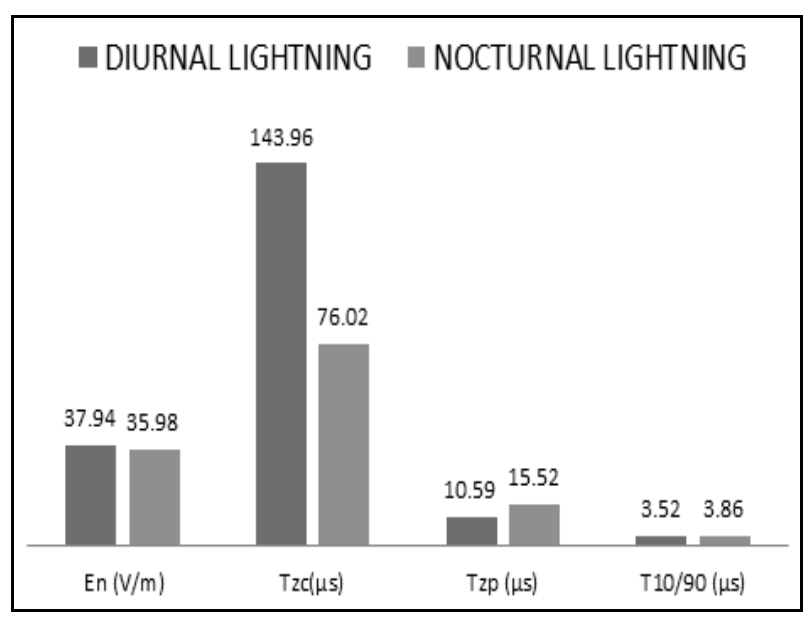

Figure 4: Comparison for SRS Parameters

\section{b) Comparison Between FRS And SRS Parameters For Diurnal And Nocturnal}

Figure 5 and Figure 6 show the comparison between FRS and SRS parameters average value for diurnal and nocturnal lightning events respectively. The largest difference is observed between their $E_{n}$ values. FRS $E_{n}$ value was $63 \%$ higher than SRS in diurnal whereas for nocturnal, FRS $E_{n}$ value was $49 \%$ higher than SRS. FRS amplitude is normally higher than SRS because it was the first excessive charges burst from the thundercloud. After the first discharge, the thundercloud consists less charges and produced lower peak amplitude for the following SRS. This finding was similar to the investigations conducted by Wooi et al. [15] and Baharudin et al. [14]. In their studies, the data were obtained from Johor, located in the southern part of Peninsula Malaysia. However, there were 3\% of SRS with $E_{n}$ higher than FRS observed in this study which will be discussed in future report. This was also observed in other studies such as by Qie et al. in China
[32] while Nag et al. [33] analyzed data obtained from Florida, Austria, Sweden and Brazil. This is most probably because of the ohmic heating effect when a larger energy transpired into the channel after the return stroke pulse [34]. The $T_{z c}$ mean values for both diurnal and nocturnal data were found in the same variation. Whereby, SRS samples were $62 \%$ and $47 \%$ higher than FRS $T_{z c}$ for diurnal and nocturnal lightning, respectively. This was due to the decreasing speed of the lightning after the first return stroke occurred. Shooray et al. suggested that lower lightning speed produced higher $T_{z c}$ [35]. Basically, the lightning speed influenced by the charge capacity which generated the lightning electric field amplitude. The higher the charge capacity the higher the peak amplitude produced in the lightning channel and vice versa [36]. According to Cooray [37] and Rakov et al. [38], the higher the total charges, the higher the lightning speed and the lower the rise time of the lightning produced. Result of this study is in agreement with the aforementioned inferences. However, zero crossing and rise time parameters variation are also influence by other factors such as soil conductivity and propagation distance as discussed in $[39,40]$. It is interesting to note that, our finding is in contrast to Wooi's work [15] which was conducted in Johor as can be seen in Table I. The $T_{z c}$ for FRS observed in Johor was 4\% higher than SRS. Besides, the mean value for FRS $T_{z p}$ was $6 \%$ higher than SRS whereas $T_{10-90}$ for FRS and SRS were $100 \%$ similar in his work. Meanwhile, this current study observed that $T_{Z P}$ and $T_{10-90}$ mean value for FRS diurnal data are $42 \%$ and $8 \%$, respectively, shorter than SRS. Nocturnal data also displays similar pattern when the FRS is shorter than SRS as much as $46 \%$ and $8 \%$ for its $T_{Z P}$ and $T_{10-90}$ mean value, respectively.

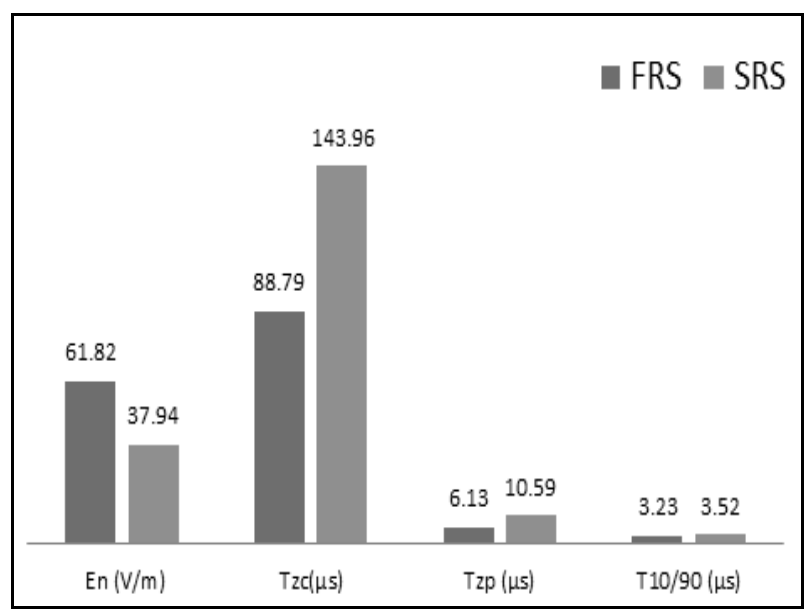

Figure 5: Average Value of Lightning Parameters for Diurnal Events 


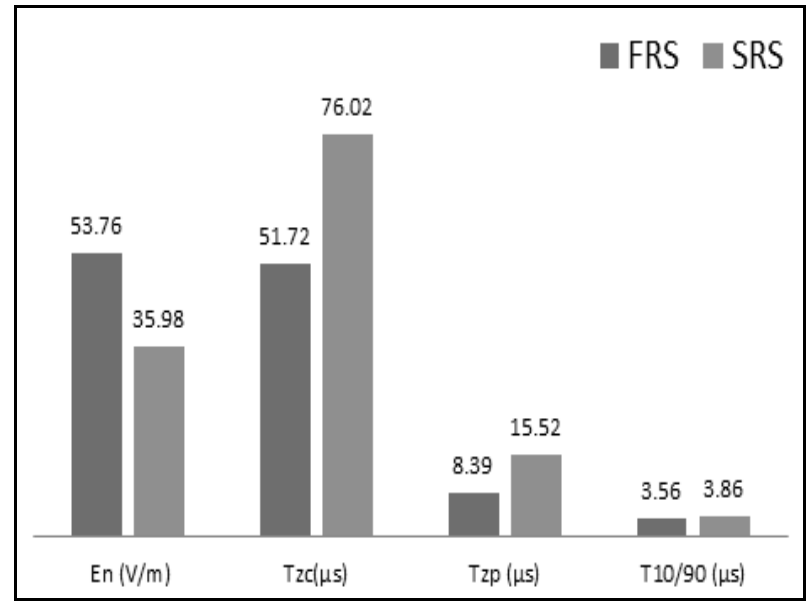

Figure 6: Average Value of Lightning Parameters for Nocturnal Events

Table 1: Lightning Parameters Comparison

\begin{tabular}{|c|c|c|c|c|c|c|}
\hline 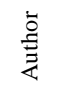 & 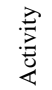 & $\begin{array}{l}\text { Return } \\
\text { Stroke }\end{array}$ & $\begin{array}{c}\mathrm{E}_{\mathrm{n}} \\
(\mathrm{V} / \mathrm{m})\end{array}$ & $\begin{array}{c}\mathrm{T}_{\mathrm{zc}} \\
(\mu \mathrm{s})\end{array}$ & $\begin{array}{c}\mathrm{T}_{\mathrm{zp}} \\
(\mu \mathrm{s})\end{array}$ & $\begin{array}{l}\mathrm{T}_{10 / 90} \\
(\mu \mathrm{s})\end{array}$ \\
\hline \multirow{4}{*}{ 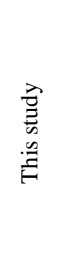 } & \multirow{2}{*}{ 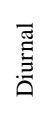 } & FRS & 61.82 & 88.79 & 6.13 & 3.23 \\
\hline & & SRS & 37.94 & 143.96 & 10.59 & 3.52 \\
\hline & \multirow{2}{*}{$\begin{array}{l}\bar{\Xi} \\
\text { 竎 } \\
\text { Z }\end{array}$} & FRS & 53.76 & 51.72 & 8.39 & 3.56 \\
\hline & & SRS & 35.98 & 76.02 & 15.52 & 3.86 \\
\hline \multirow{2}{*}{$\overrightarrow{8} \cong$} & \multirow{2}{*}{$\overleftrightarrow{z}$} & FRS & 21.80 & 50.70 & 6.60 & 3.90 \\
\hline & & SRS & 12.70 & 48.90 & 6.20 & 3.90 \\
\hline
\end{tabular}

In a nutshell, temperature and humidity differences are the most influencing factor when discussing about diurnal and nocturnal lightning data variations. Higher temperature tends to produce lower humidity and creates drier air. This combination leads to a higher electrostatic discharge like lightning phenomenon [41]. Therefore, diurnal lightning tends to generate higher $E_{n}$ because of higher surface temperature compared to nocturnal. Yet, there were some lightning events that produced higher $E_{n}$ during cold and nighttime. It was most probably due to drier cold season and nighttime compared to summer and daytime respectively. FRS normally produced higher $E_{n}$ than SRS comparatively. This is because the first lightning discharge contents more electrical charges compared to the following events. There is a condition called ohmic heating effect, when more charges burst into the lightning channel after return stroke. This condition might produce higher SRS amplitude than FRS. Based on Heidler's work [39], lightning propagation distance substantially influence the signal $T_{Z C}$. Thus, for a vertical channel termination lightning event, the higher the cloud base height the longer the $T_{z c}$. Cloud base height can be estimated by using surface temperature and dew point as comprehensively derived in [42]. The more the difference between those temperatures the higher the cloud base height which is normally occurred during daytime. Thus, diurnal lightning tends to produced longer $T_{z c}$. Besides, than lightning propagation distance, this parameter also affected to the speed of lightning propagation. The higher the speed of lightning the shorter the value of $T_{z C}$. High speed lightning is produced by high total charges consist in the lightning channel. Thus FRS which content more electrical charges than SRS produced shorter $T_{z c}$. Similarly, due to the decreasing charges and speed after the FRS, $T_{z P}$ and $T_{10-90}$ in SRS are likely to be longer than FRS. Besides, both parameters are also influenced by temperature variations. Lightning occurred during higher temperature as in daytime tends to produce shorter $T_{Z p}$ and $T_{10-90}$ compared to the lightning occurred at night.

\section{CONCLUSION}

Analysis of the characteristics between FRS and SRS occurred during the day and night was conducted. Four important parameters namely normal electric field peak voltage $\left(E_{n}\right)$, zero crossing time $\left(T_{z c}\right)$, zero to peak rise time $\left(T_{Z P}\right)$ and $10 \%$ to $90 \%$ rise time $\left(T_{10-90}\right)$ were analyzed from 40 samples in total. The variation pattern of FRS and SRS for diurnal was similar to nocturnal. Mean value for $E_{n}$ of FRS is higher compared to SRS by a factor of 1.63 and 1.53 for diurnal and nocturnal respectively. All the rise time parameters in diurnal and nocturnal events, namely the $T_{Z C}, T_{Z P}$ and $T_{10-90}$ were shorter for FRS compared to SRS by a factor in range of 0.55 to 0.96 . Besides, the samples also used to identify the variation of FRS characteristics in diurnal and nocturnal events and SRS characteristics in both aforementioned lightning events. Again, the variation pattern of FRS for diurnal and nocturnal was similar to the variation in SRS. Both parameters of $E_{n}$ and $T_{z c}$ are higher in FRS for diurnal lightning compared to nocturnal. Further, diurnal FRS peak is higher by a factor of 1.12 compared to nocturnal FRS whereas the $T_{z c}$ for diurnal FRS is a factor of 1.83 higher from nocturnal FRS samples. Another two rise time characteristics for FRS diurnal lightning events were shorter compared to nocturnal. It was obtained that the $T_{z P}$ and $T_{10-90}$ mean value were shorter by the factor of 0.68 and 0.91 respectively. Similarly, the $E_{n}$ and $T_{z c}$ for SRS in diurnal events were higher than nocturnal SRS. The differences were by the factor of 1.05 for the $E_{n n}$ and 1.89 for the $T_{z c}$ mean value. The $T_{z p}$ and $T_{10-90}$ for diurnal lightning SRS were also shorter compared to nocturnal. By the factor of $0.68, T_{Z P}$ for SRS diurnal 
samples was shorter than nocturnal whereas the $T_{10-90}$ in SRS diurnal was shorter by 0.91 than nocturnal.

Interestingly, this experimental work had enhanced the understanding on the variations of diurnal and nocturnal lightning important characteristics. The most obvious difference features of days and nights are temperature and humidity. Therefore, most probably those factors highly influenced the lightning characteristics variations as observed in this study. Significantly, the peak electric field of the first return stroke in diurnal events was considered as the strongest peak and this observation is important to a better design of the lightning protection system.

\section{ACKNOWLEDGMENT}

Authors would like to acknowledge University College of Technology Sarawak (UCTS) for the financial support to carry out this study, and also the expertise and technology from Universiti Teknologi Malaysia (UTM) This work was funded by UCTS research grant, [ID: UCTS/RESEARCH/2/2018/06].

\section{REFERENCES}

[1] L. Smith, "Types of Lightning," National Geographic: The Impact of a Lightning Strike, 2019.

[2] S. Shivalli, "Lightning Phenomenon, Effects and Protection of Structures from Lightning," IOSR Journal of Electrical and Electronics Engineering (IOSRJEEE), vol. 11, pp. 23203331, 2016.

[3] D. Johari, V. Cooray, M. Rahman, P. Hettiarachchi, and M. M. Ismail, "Features of the first and the subsequent return strokes in positive ground flashes based on electric field measurements," Electric Power Systems Research, vol. 150, pp. 55-62, 2017.

[4] D. Robinson, "Lightning Types and Classifications," In-depth look at cloud-toground lightning, 2015.

[5] C. Wagner and G. McCann, "Lightning phenomena: I-General characteristics," Electrical Engineering, vol. 60, no. 8, pp. 374384, 1941.

[6] V. Cooray and S. Lundquist, "On the characteristics of some radiation fields from lightning and their possible origin in positive ground flashes," Journal of Geophysical Research: Oceans, vol. 87, no. C13, pp. 11203-11214, 1982.

[7] V. Rakov, "A review of positive and bipolar lightning discharges," Bulletin of the American
Meteorological Society, vol. 84, no. 6, pp. 767-776, 2003.

[8] C. Schumann and M. M. Saba, "Continuing current intensity in positive ground flashes," in 2012 International Conference on Lightning Protection (ICLP), 2012, pp. 1-5: IEEE.

[9] V. Rakov et al., "CIGRE technical brochure on lightning parameters for engineering applications," in 2013 International Symposium on Lightning Protection (XII SIPDA), 2013, pp. 373-377: IEEE.

[10] C.-L. Wooi, Z. Abdul-Malek, B. Salimi, N. A. Ahmad, K. Mehranzamir, and S. VahabiMashak, "A comparative study on the positive lightning return stroke electric fields in different meteorological conditions," Advances in Meteorology, vol. 2015, 2015.

[11] K. Mehranzamir, Z. Abdul-Malek, B. Salimi, and N. A. Ahmad, "Observation of Isolated Breakdown Lightning Flashes in a Tropical Region," in Applied Mechanics and Materials, 2014, vol. 554, pp. 583-587: Trans Tech Publ.

[12] M. Esa, M. R. Ahmad, V. Cooray, and M. R. M. Esa, "Occurrence of narrow bipolar pulses between negative return strokes in tropical thunderstorms," in 2014 International Conference on Lightning Protection (ICLP), 2014, pp. 1141-1142: IEEE.

[13] N. A. Ahmad, M. Fernando, Z. A. Baharudin, V. Cooray, H. Ahmad, and Z. A. Malek, "Characteristics of narrow bipolar pulses observed in Malaysia," Journal of Atmospheric and Solar-Terrestrial Physics, vol. 72, no. 5-6, pp. 534-540, 2010.

[14] Z. A. Baharudin, N. A. Ahmad, J. Mäkelä, M. Fernando, and V. Cooray, "Negative cloud-toground lightning flashes in Malaysia," Journal of Atmospheric and Solar-Terrestrial Physics, vol. 108, pp. 61-67, 2014.

[15] C.-L. Wooi, Z. Abdul-Malek, N.-A. Ahmad, and A. I. El Gayar, "Statistical analysis of electric field parameters for negative lightning in Malaysia," Journal of Atmospheric and Solar-Terrestrial Physics, vol. 146, pp. 69-80, 2016.

[16] M. N. Hamzah, M. Z. A. Ab Kadir, C. Gomes, and S. N. M. Arshad, "Unique StrokeMultiplicity of Positive Lightning in Malaysia," in Applied Mechanics and Materials, 2015, vol. 793, pp. 39-43: Trans Tech Publ.

[17] Z. A. Baharudin, N. A. Ahmad, M. Fernando, V. Cooray, and J. Mäkelä, "Comparative study on preliminary breakdown pulse trains observed in Johor, Malaysia and Florida, 
USA," Atmospheric research, vol. 117, pp. 111-121, 2012.

[18] N. A. B. Ramlee, N. Ahmad, M. Esa, Z. Malek, Z. Adzis, and Z. Nordeen, "Characteristics of Positive Lightning As Observed In Temperate and Tropic Regions: A Review," in 2018 2nd International Conference on Electrical Engineering and Informatics (ICon EEI), 2018, pp. 159-164: IEEE.

[19] L. T. Know, "Diurnal and Nocturnal," Love To Know: Your Dictionary, 2020.

[20] M. F. Arturo Galvan, "Operative Characteristics Of A Parallel-Plate Antenna To Measure Vertical Electric Field From Lightning Flashes," Uppsala University, 2000.

[21] G. Jones, "Sunrise and Sunset in Malaysia," Time and Date: Sun and Moon, 2017.

[22] J. L. Canty, "Sibu Weather," Sibu Climate Summary by Weatherbase, 2020.

[23] K. Miyake, T. Suzuki, and K. Shinjou, "Characteristics of winter lightning current on Japan Sea coast," IEEE Transactions on power Delivery, vol. 7, no. 3, pp. 1450-1457, 1992.

[24] I. Pinto, O. Pinto Jr, R. Rocha, J. Diniz, A. Carvalho, and A. C. Filho, "Cloud - to - ground lightning in southeastern Brazil in 1993: 2. Time variations and flash characteristics," Journal of Geophysical Research: Atmospheres, vol. 104, no. D24, pp. 31381-31387, 1999.

[25] D. Zheng, Y. Zhang, Q. Meng, L. Chen, and J. Dan, "Climatological comparison of small-and large-current cloud-to-ground lightning flashes over Southern China," Journal of Climate, vol. 29, no. 8, pp. 2831-2848, 2016.

[26] T. Chronis et al., "Climatological diurnal variation of negative CG lightning peak current over the continental United States," Journal of Geophysical Research: Atmospheres, vol. 120, no. 2, pp. 582-589, 2015.

[27] C. D. Ahrens, Meteorology today: an introduction to weather, climate, and the environment. Cengage Learning, 2012.

[28] G. V. Cooray, TheLightning Flash (no. 34). Iet, 2003.

[29] M. Ishii and J. I. Hojo, "Statistics on fine structure of cloud - to - ground lightning field waveforms," Journal of Geophysical Research: Atmospheres, vol. 94, no. D11, pp. 13267-13274, 1989.

[30] A. Nag and V. A. Rakov, "Parameters of electric field waveforms produced by positive lightning return strokes," IEEE Transactions on Electromagnetic Compatibility, vol. 56, no. 4, pp. 932-939, 2014.

[31] C. Schumann, M. M. F. Saba, R. B. G. Da Silva, and W. Schulz, "Electric fields changes produced by positives cloud-to-ground lightning flashes," Journal of Atmospheric and Solar-Terrestrial Physics, vol. 92, pp. 37-42, 2013.

[32] X. Qie, Y. Yu, D. Wang, H. WANG, and R. Chu, "Characteristics of cloud-to-ground lightning in Chinese inland plateau," Journal of the Meteorological Society of Japan. Ser. II, vol. 80, no. 4, pp. 745-754, 2002.

[33] A. Nag et al., "First versus subsequent return-stroke current and field peaks in negative cloud - to - ground lightning discharges," Journal of Geophysical Research: Atmospheres, vol. 113, no. D19, 2008.

[34] M. Tran and V. Rakov, "Attachment process in subsequent strokes and residual channel luminosity between strokes of natural lightning," Journal of Geophysical Research: Atmospheres, vol. 120 , no. 23 , pp. 12,24812,258, 2015.

[35] A. Shoory, F. Rachidi, M. Rubinstein, R. Moini, and S. H. H. Sadeghi, "Analytical expressions for zero-crossing times in lightning return-stroke engineering models," IEEE transactions on electromagnetic compatibility, vol. 51, no. 4, pp. 963-974, 2009.

[36] G. Lu, S. A. Cummer, R. J. Blakeslee, S. Weiss, and W. H. Beasley, "Lightning morphology and impulse charge moment change of high peak current negative strokes," Journal of Geophysical Research: Atmospheres, vol. 117, no. D4, 2012.

[37] V. Cooray, "A model for subsequent return strokes," Journal of Electrostatics, vol. 30, pp. 343-354, 1993.

[38] V. Rakov and A. Dulzon, "A modified transmission line model for lightning return stroke field calculations," in Proc. 9th Int. Symp. Electromagn. Compat, 1991, pp. 229235.

[39] F. H. Heidler and C. Paul, "Field Enhancement by Lightning Strikes to Tall Tower Versus Lightning Strikes to Flat Ground," IEEE Transactions on Electromagnetic Compatibility, 2020.

[40] Y. Zhang, J. Gu, and E. Zhang, "Analysis of underground propagation effects of lightning electromagnetic fields in different geological environments," International Journal of Applied Electromagnetics and Mechanics, no. Preprint, pp. 1-13, 2020. 
Characteristics of Diurnal and Nocturnal Lightning Activities in Sarawak, Malaysia

[41] Condair, "Why Does Low Humidity Cause Static Electricity?," Understanding How Static Electricity is Formed, 2019.
[42] M. G. Lawrence, "The relationship between relative humidity and the dewpoint temperature in moist air: A simple conversion and applications," Bulletin of the American Meteorological Society, vol. 86, no. 2, pp. 225-234, 2005. 